\title{
Pemanfaatan Augmented Reality Dalam Dunia Pendidikan Untuk Mengenal Spesies Burung di Indonesia Berbasis Android
}

\author{
Agung Kurniawan, Ali Mahmudi, Mira Orisa \\ Program Studi Teknik Informatika S1, Fakultas Teknologi Industri \\ Institut Teknologi Nasional Malang, Jalan Raya Karanglo km 2 Malang, Indonesia \\ agung1618906@gmail.com
}

\begin{abstract}
ABSTRAK
Setiap jenis hayati harus tetap dipertahankan fungsi dan keberadaannya, termasuk salah satunya yakni satwa burung. Di Indonesia sendiri memiliki 1.531 jenis burung dan 397 diantaranya endemik. Namun sayangnya, ada beberapa burung yang terancam punah, karena maraknya perburuan dan perdagangan liar. Sehingga generasi muda saat ini tidak memiliki pengetahuan terkait jenis burung. Berdasarkan masalah yang telah disebutkan maka penulis bermaksud untuk menggunakan teknologi yang telah dikembangkan saat ini yaitu Augmented Reality sebagai upaya untuk mengatasi masalah tersebut.

Dengan memanfaatkan Teknologi Augmented Reality dalam memperkenalkan spesies burung di Indonesia menggunakan metode marker berbasis Android. Untuk pembuatan aplikasi digunakan Unity dengan Vuforia, untuk pembuatan objek 3D digunakan aplikasi Blender 3D sebagai pemodelan objek burung.

Hasil akhir dari penelitian ini berupa aplikasi pemanfaatan Augmented Reality dalam pendidikan untuk mengenal spesies burung di Indonesia berbasis android, pada penelitian ini peneliti berhasil membuat memiliki rata-rata waktu load untuk memunculkan objek yaitu 2.5 detik. Sedangkan untuk minimal versi android untuk menggunakan aplikasi adalah Lollipop dengan RAM 4 GB. Untuk jarak deteksi dengan jarak yaitu $10 \mathrm{~cm}, 30$ $\mathrm{cm}$, dan $50 \mathrm{~cm}$. Pengujian jarak terhadap marker, jarak ideal agar marker dapat ter-scan dengan baik adalah antara $10 \mathrm{~cm}, 30 \mathrm{~cm}$, sedangkan pada jarak $50 \mathrm{~cm}$ marker tidak dapat terdeteksi. Dari hasil intensitas cahaya adalah pada nilai 2,7 $C d, 3,6 C d$, dan 6,4 $C d$ marker dapat terdeteksi dengan baik. Sedangkan nilai intensitas 65,6 $C d$ marker dapat terdeteksi namun load lama.
\end{abstract}

Kata Kunci : Augmented Reality, Metode Marker, spesies burung

\section{PENDAHULUAN}

Setiap jenis hayati memiliki fungsi dalam melestarikan ekosistem yang ditempati, maka dari itulah setiap jenis hayati harus tetap dipertahankan fungsi dan keberadaannya (Sulistyadi, 2010). Indonesia merupakan negara yang memiliki keanekaragaman hayati yang tidak kalah dengan negara lain di dunia, seperti Brazil. Yang lebih menarik, Indonesia terdapat wilayah wallacea yang didalamnya terkandung endemisitas dengan tingkat keanekaragaman yang tinggi (Supriatna, 2008). Menurut identifikasi dari Birdlife International, berdasarkan pola endemisitas spesies dan penyebaran yang terbatas terdapat 218 Daerah Burung Endemik dan $10 \%$ terdapat di Negara Indonesia dengan proporsi tertinggi di kawasan Wallacea (Nusa Tenggara, Maluku, dan Sulawesi) (Hamzati \& Aunurohim, 2013). Jika dilihat dari data statistik, Indonesia menempati urutan kelima untuk keanekaragaman burung (1.531 jenis dan 397 endemik). Bahkan khusus untuk keanekaragaman burung paruh bengkok, Indonesia menempati urutan pertama (75 jenis, 38 endemik) (Supriatna, 2008). Sayangnya, terdapat beberapa jenis burung di Indonesia terancam punah. Menurut penelitian dari (Ohan \& Budiawati, 2015), salah satu penyebab dari langkanya satwa burung yakni akibat dari adanya kontes burung kicau. Karena adanya kontes burung tersebut mengakibatkan meningkatnya perdagangan burung dan maraknya perburuan liar. Namun sisi positif dari adanya kontes burung tersebut yakni mengembangkan pengetahuan masyarakat terkait ragam/ jenis burung. Bergerak dari permasalahan inilah, peneliti mencoba membuat aplikasi yang bisa mengembangkan pengetahuan masyarakat terkait ragam/ jenis burung tanpa melakukan pemburuan liar yang justru mengancam kelestarian jenis burung itu sendiri. Dalam pembuatan aplikasi ini diperlukan suatu teknologi yang disebut dengan Augmented Reality (AR). Augmented Reality (AR) adalah teknologi yang dapat menggambarkan dan menggabungkan dunia nyata dengan dunia maya yang diproyeksikan melalui perangkat elektronik. Dengan begitu pengguna dapat memanfaatkan Augmented Reality (AR) sebagai media pembelajaran dan ilmu pengetahuan untuk mengenal jenis-jenis Burung di Indonesia.

Jenis metode penelitian yang digunakan yakni metode penelitian deskriptif, dimana penelitian deskriptif merupakan suatu metode yang menggambarkan dan menginterpretasi objek apa adanya. Pada eksperimen yang dilakukan, digunakan media cetak buku gambar burung yang telah disisipi marker. Sedangkan metode pengumpulan data dilakukan dengan cara library research, yaitu pengumpulan data referensi yang berasal dari buku. Metode Augmented Reality yang digunakan yaitu Marker Based Tracking, yaitu Marker dengan ilustrasi hitam dan putih persegi dengan batas hitam tebal dan latar belakang putih (Asry, 2019).

Dalam pembuatan aplikasi ini, alat yang digunakan yakni Blender 3D sebagai pemodelan objek 3D, Vuforia sebagai database marker, dan Unity sebagai pembangunan 
aplikasi. Pemodelan objek 3D yang digunakan yakni poligon, nurbs, curve, primitif, dan sculpting.

Hasil akhir dari penelitian ini berupa aplikasi pemanfaatan Augmented Reality dalam pendidikan untuk mengenal spesies burung di Indonesia berbasis android, pada penelitian ini peneliti berhasil membuat memiliki rata-rata waktu load untuk memunculkan objek yaitu 2.5 detik. Sedangkan untuk minimal versi android untuk menggunakan aplikasi adalah Lollipop dengan RAM 4 GB. Untuk jarak deteksi dengan jarak yaitu $10 \mathrm{~cm}, 30 \mathrm{~cm}$, dan $50 \mathrm{~cm}$. Pengujian jarak terhadap marker, jarak ideal agar marker dapat ter-scan dengan baik adalah antara 10 $\mathrm{cm}, 30 \mathrm{~cm}$, sedangkan pada jarak $50 \mathrm{~cm}$ marker tidak dapat terdeteksi. Dari hasil intensitas cahaya adalah pada nilai 2,7 Cd, 3,6 Cd, dan 6,4 Cd marker dapat terdeteksi dengan baik. Sedangkan nilai intensitas 65,6 Cd marker dapat terdeteksi namun load lama.

\section{TINJAUAN PUSTAKA}

\subsection{Penelitian Terdahulu}

Menurut (Wiguna, 2019), pada dasarnya untuk mempelajari alat musik tradisional cukup dilakukan hanya melalui buku. Namun dengan Augmented Reality diharapkan dapat membuat sistem pembelajaran seni budaya termasuk alat musik tradisional menjadi lebih menarik. Hal ini disebabkan karena Augmented Reality dapat menjadi alat peraga alat musik tradisional dalam bentuk 3D.

Menurut (Avis, 2011), Pada penelitiannya bertujuan untuk mengimplementasikan teknologi augmented reality dalam bidang pemasaran yang akan menampilkan produk Kawasaki Surapita Unitrans malang dalam bentuk 3D berbasis android serta membantu Kawasaki memasarkan produknya dengan cara menampilkan produknya berupa gambar 3D dengan menggunakan teknologi augmented reality.

Menurut (Sabilillah, 2018), Metode Augmented Reality dapat digunakan untuk membuat aplikasi pengenalan rambu-rambu lalu lintas. Dimana dengan Metode Augmented Reality dapat memberikan sebuah desain yang menarik dan mudah dipahami oleh pengguna. Karena memberikan informasi lalu lintas berupa gambar, animasi, objek 3D, dan informasi suara. Dengan desain yang menarik dan mudah dipahami bagi pengguna, diharapkan aplikasi ini dapat memberikan ilmu pengetahuan terkait rambu lalu lintas, sehingga dapat mengurangi jumlah pelanggar lalu lintas dan meminimalisir kecelakaan.

Pada penelitian (Defandra, 2010), memanfaatkan Metode marker based tracking untuk mebuat suatu aplikasi animasi 3D. Aplikasi tersebut memuat informasi mengenai beberapa relief yang ada pada candi Borobudur dengan tujuan sebagai sarana pembelajaran sejarah candi di Indonesi dalam bentuk animasi 3D. Seperti penelitian kebanyakan mengenai augmented reality menggunakan Metode marker based tracking. Faktor cahaya dan jarak marker sangat menentukan keberhasilan dari penggunakan fitur scan marker pada aplikasi.
(Sudarmilah \& dkk, 2015) telah berhasil memadupadankan teknologi terkini dengan sistem pembelajaran dan materi yang terbarukan. Pada game yang telah dibuat telah disisipkan materi pembelajaran mengenai senjata tradisional Indonesia. Sehigga selain dengan visualisasi game adventure yang menarik, tetaoi juga dapat menyajikan materi tentang keberagaman budaya yang dapat membuat siswa lebih bisa memahami materi pembelajaran khususnya senjata tradisional Indonesia.

(Andriansyah, 2012) menggunakan marker based tracking dan penelitian sendiri di fokuskan sebagai sarana pelestarian budaya senjata Banten. Selain objek dan marker, spesifikasi sistem ataupun hardware sangat berpengaruh agar aplikasi dapat berjalan dengan lancar. Untuk system disarankan minimal menggunakan OS v4.4 Kitkat, snapdragon 410, RAM 1 GB dan kamera 8MP agar marker dapat terdeteksi dengan baik.

\subsection{Dasar Teori}

\subsubsection{Augmented Reality}

Augmented Reality (AR) merupakan istilah untuk suatu teknologi yang menggabungkan antara dunia nyata dengan virtual untuk kemudian diproyeksikan dalam waktu yang nyata (real-time). Dengan teknologi AR, lingkungan nyata di sekitar akan dapat berinteraksi dalam bentuk digital (virtual). Informasi tentang objek dan lingkungan sekitar dapat ditambahkan ke dalam sistem AR yang kemudian akan ditampilkan pada layar dunia nyata secara realtime seolah-olah informasi tersebut nyata. AR memiliki banyak potensi di dalam industri dan penelitian akademis. (Candra, 2014)

Tujuan dari AR adalah mengambil dunia nyata sebagai dasar dengan menggabungkan beberapa teknologi virtual dan menambahkan data konstektual agar pemahaman manusia sebagai penggunanya menjadi semakin jelas. Data konstektual ini dapat berupa komentar audio, data lokasi, konteks sejarah, atau dalam bentuk lainnya. Pada saat ini, AR telah banyak digunakan dalam berbagai bidang seperti kedokteran, militer, manufaktur, hiburan, museum, pendidikan, dan lain-lain (Rahmat, 2011).

\subsubsection{Vuforia}

Vuforia merupakan library Augmented Reality Software Development Kit (SDK) yang digunakan sebagai pendukung adanya augmented reality pada android. Vuforia dapat menghasilkan informasi 3D dari gambar yang telah dianalisa menggunakan pendeteksi marker dan marker yang telah terdeteksi. SDK ini menggunakan teknologi computer vision untuk mengenali dan melacak gambar planar (Gambar Target) dan objek 3D sederhana, seperti kotak, secara real-time. Dengan teknologi Augmented Reality, vuforia dapat merubah kertas dengan latar kosong menjadi tampilan dengan grafis 3D yang menarik. Developer juga dapat menggunakan vuforia untuk memaksimalkan 
kemampuan teknologi augmented reality dalam menciptakan suatu konten, seperti game, aplikasi, iklan, dan persentasi. Aplikasi bahasa pemrograman yang disediakan oleh vuforia meliputi java, Aplication Programming (API) di C++, bahasa Net, dan Objective-C. (Purnawati, 2001)

\subsubsection{Android}

Sistem operasi perangkat mobile berbasis linux yang mencakup sistem aplikasi, middleware dan operasi disebut dengan android. Dimana sistem ini menyediakan platform untuk para developer untuk membuat atau menciptakan suatu aplikasi. Generasi baru platform mobile inilah yang memberikan kesempatan bagi developer untuk melakukan suatu pengembangan sesuai dengan apa yang diharapkan. (Kurniawan, 2011)

\subsubsection{Image Target}

Gambar yang dapat dilacak dan terdeteksi oleh Vuforia SDK disebut dengan image target. Image target dapat dikenali oleh Vuforia SDK dengan membandingkan fitur dalam gambar fisik dengan gambar didalam database aplikasi. Untuk mendeteksi dan melacak fitur yang ditemukan didalam sebuah gambar secara natural, maka vuforia SDK akan mengaplikasikan algoritma khusus. SDK akan melacak gambar selama berada di sudut pandang kamera. Ketika gambar terdeteksi, Vuforia SDK hanya melacak fitur detail sudut pada gambar. (Mustaqim \& Kurniawan, 2017)

\subsubsection{Unity 3D 2018.3}

Unity adalah sebuah bentuk teknologi terbaru yang meringankan dan memudahkan game develop dalam membuat game. Unity 3D juga dapat digunakan untuk membuat konten yang interaktif lainya seperti, real-time 3D animasi dan visual arsitektur. (Andriansyah, 2012)

\section{ANALISIS DAN PERANCANGAN}

\subsection{Blok Diagram Sistem}

Blok

diagram adalah diagram dari sebuah sistem, di mana bagian utama atau fungsi yang diwakili oleh blok dihubungkan dengan garis, yang menunjukkan hubungan dari blok. Proses kerja di gambar 3.1 berikut.

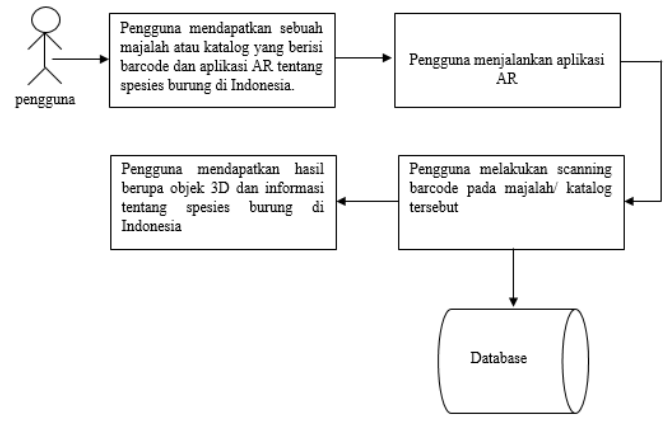

Gambar 3.1 Blok diagram sistem
Pada blok diagram system dapat diketahui langkah awal sebelum menjalankan aplikasi yaitu user mempunyai katalog yang berisi marker dan informasi mengenai aplikasi Pemanfaatan Augmented Reality Dalam Dunia Pendidikan Untuk Mengenal Spesies Burung di Indonesia Berbasis Android. Kemudian user menjalankan aplikasi dan memilih Bahasa kemudian melakukan scan, dimana marker akan di scan kemudian system akan mengambil informasi berupa objek 3D dari database.

\subsection{Flowchart sistem}

Flowchart sistem menjelaskan proses berjalananya aplikasi yang terlihat Gambar 3.2 berikut.

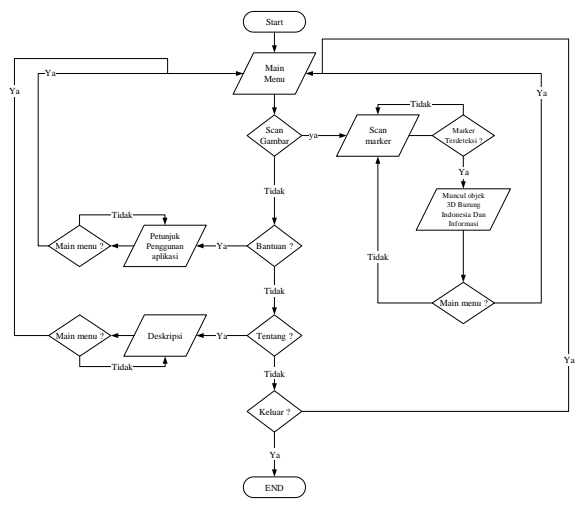

Gambar 3.2 Flowchart sistem

Pada flowchart sistem di atas proses dimulai dari start yaitu splash screen pada aplikasi. Kemudian masuk pada halaman pemilihan Bahasa. Selanjutnya adalah halaman scan marker yang langsung terhubung dengan kamera smartphone. Setelah melakukan scan marker dan jika marker sesuai maka akan muncul objek 3D dan informasi deskripsi berupa audio yang dapat di akses melalui button narasi. Selanjutnya terdapat fitur bantuan yang berisi cara penggunaan aplikasi. Terdapat fitur tentang yang berisi deskripsi aplikasi dan profil developer. Dan proses berakhir apabila menekan tombol keluar aplikasi atau end pada flowchart.

\subsection{Flowchart Augmented Reality}

Flowchart augmented reality ini menjelaskan proses pembacaan marker pada sistem augmented reality pada Gambar 3.3. 


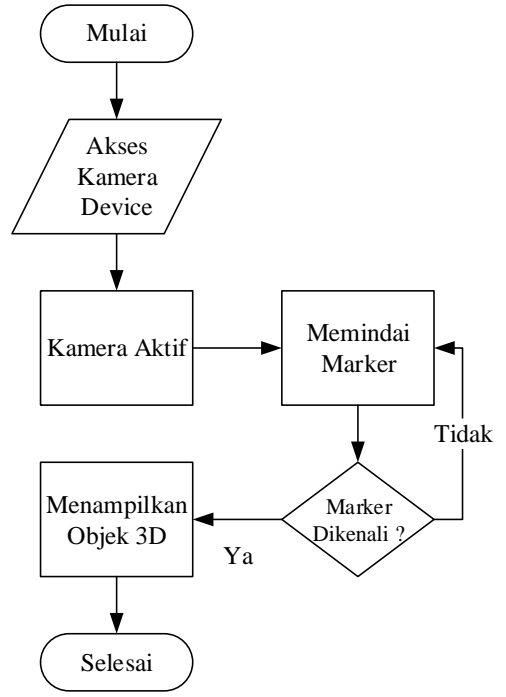

Gambar 3.3 Flowchart augmented reality

Proses pendeteksi marker dimulai dengan pembacaan marker oleh kamera smartphone. Kemudian kamera akan mendeteksi marker. Deteksi pada marker tergantung pada intensitas cahaya, jarak, dan resolusi. Jika marker tidak terdeteksi, maka user harus mengatur marker. Jika marker terdeteksi maka akan muncul objek 3D.

\section{HASIL DAN PEMBAHASAN}

\subsection{Hasil Tampilan Awa}

Tampilan awal pada aplikasi ini merupakan tampilan Мепи home sebelum masuk ke tampilan menu kedua. Berikut tampilan Мепи home Gambar 4.1.

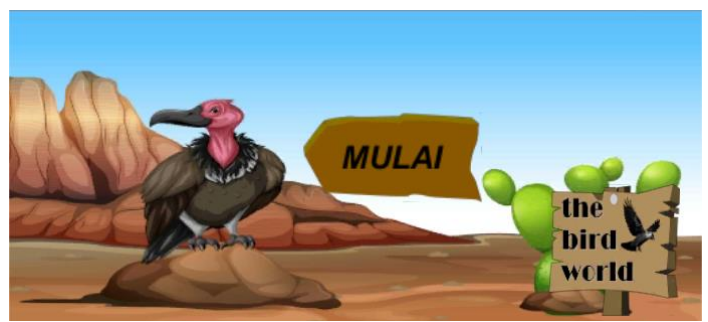

Gambar 4.1 Tampilan Menu home

\subsection{Hasil Tampilan Pilih Menu}

Tampilan kedua aplikasi ini tampilan menu yang digunakan. Pada tampilan menu ini terdiri 5 button yaitu kamera, kuis, tentang, keluar dan bantuan.

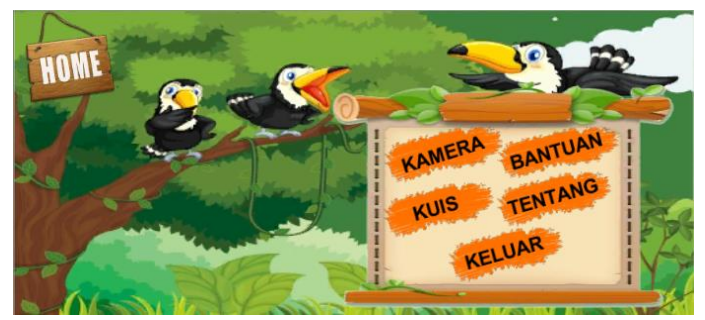

Gambar 4.2 Tampilan pilihan menu

\subsection{Hasil Tampilan Scan Marker}

Tampilan menu scan marker langsung tersambung dengan kamera. Tampilan menu mulai ini terdapat button kembali seperti pada Gambar 4.3 berikut.

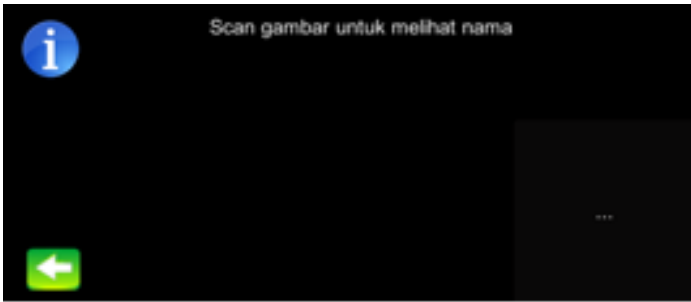

Gambar 4.3 Tampilan scan marker

Pada saat marker di hadapan kamera aplikasi, akan otomatis mendeteksi dan akan menampilan objek 3D. Desain halaman tersebut pada Gambar 4.4.

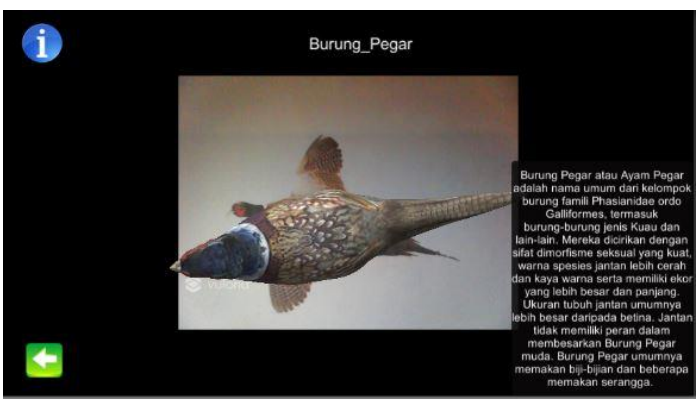

Gambar 4.4 Tampilan objek 3D burung pegar

\subsection{Hasil Tampilan Menu Kuis}

Tampilan kuis menyediakan permainan dalam bentuk puzzle acak kata (Wordl Scramble) yang lebih gampang dan mudah dipahami dengan fitur skor.
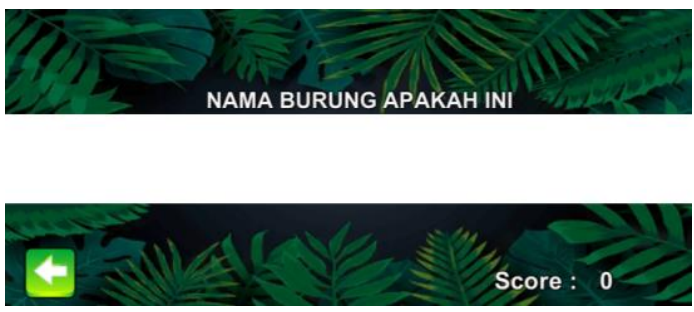

Gambar 4.5 Tampilan awal kuis

Kuis puzzle acak kata dibuat dengan bentuk acak huruf agar lebih menarik dengan dilengkapi button kembali. Pada Gambar 4.6.

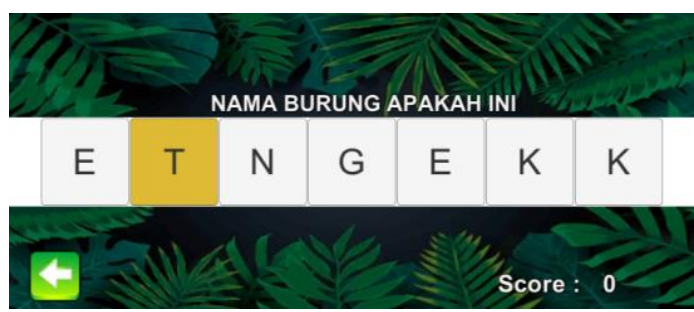

Gambar 4.6 Tampilan soal kuis 
Hasil kuis puzzle acak kata akan menampilkan skor setelah selesai mengerjaan soal atau belum selesai. Ditunjuakan pada Gambar 4.7.
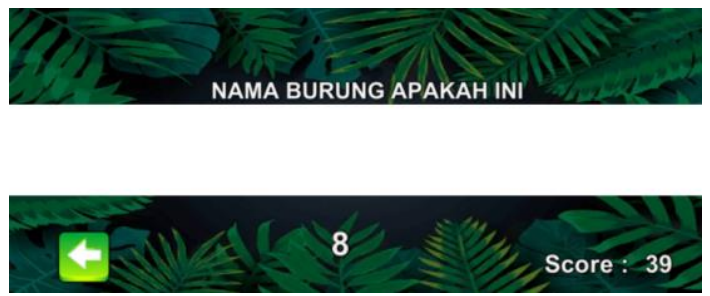

Gambar 4.7 Tampilan akhir kuis

\subsection{Hasil Tampilan Menu Tentang}

Tampilan menu tentang berisi informasi mengenai profil dari pengembang aplikasi Dilengkapi dengan button kembali. Seperti pada Gambar 4.8 berikut.

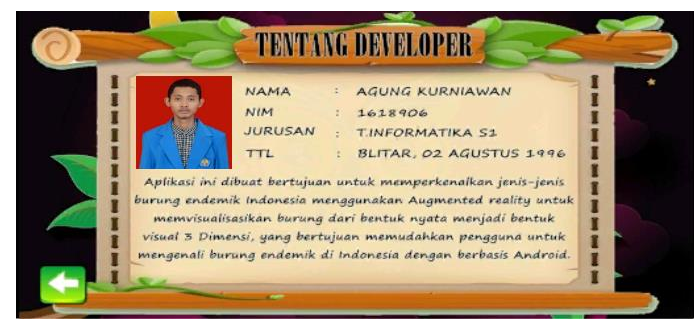

Gambar 4.8 Tampilan menu tentang

\subsection{Hasil Tampilan Menu Bantuan}

Tampilan menu bantuan ini berisi cara penggunaan aplikasi yang dilengkapi dengan. button kembali yang langsung mengarah pada tampilan ke dua menu seperti. Gambar 4.9.

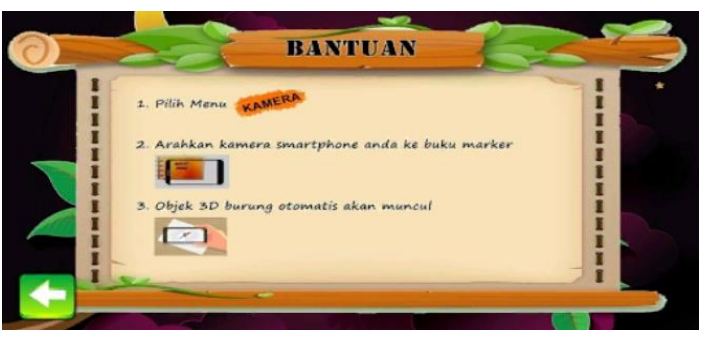

Gambar 4.9 Tampilan menu bantuan

\subsection{Pengujian Deteksi Jarak}

Kesimpulan hasil akhir pengujian marker berdasarkan jarak dekat $(10 \mathrm{~cm})$, sedang $(20 \mathrm{~cm})$, jauh $(30 \mathrm{~cm})$, sangat jauh $(40 \mathrm{~cm})$. Dengan perolehan pengujian pada deteksi marker 30 burung dari jarak $10 \mathrm{~cm}$ terdeteksi semua, untuk sedang $(20 \mathrm{~cm})$ terdapat 30 burung, untuk $(30 \mathrm{~cm})$ hanya 24 burung yang terdeteksi. Dari pengujian jarak $(40 \mathrm{~cm})$ hanya 1 burung yang dapat terdeteksi. Uji coba jarak terhadap marker dapat diketahui jarak ideal agar marker dapat ter-scan dengan baik adalah antara 10 $\mathrm{cm}, 20 \mathrm{~cm}$ sampai dengan $30 \mathrm{~cm}$, sedangkan pada jarak $40 \mathrm{~cm}$ marker tidak dapat terdeteksi dengan baik karena terdapat kendala pada marker yang di scan tidak dapat terdeteksi secara jelas dan detail.
Tabel 4.1 Pengujian Jarak

\begin{tabular}{|c|c|c|c|c|c|}
\hline \multirow[b]{2}{*}{ No } & \multirow[b]{2}{*}{ Nama Hewan } & \multicolumn{4}{|c|}{ Keterangm Jarak } \\
\hline & & $\begin{array}{l}\text { Dekat } \\
(10 \mathrm{~cm})\end{array}$ & $\begin{array}{l}\text { Sedang } \\
(20 \mathrm{~cm})\end{array}$ & $\begin{array}{c}\text { Lumayan } \\
\text { Jesh } \\
(30 \mathrm{~cm})\end{array}$ & $\begin{array}{l}\text { Joulh } \\
(40 \mathrm{~cm})\end{array}$ \\
\hline 1. & Burng Walik Jambu & $\checkmark$ & $\checkmark$ & $\checkmark$ & $\checkmark$ \\
\hline 2. & Burung Tengkek & $\checkmark$ & $\checkmark$ & $\checkmark$ & • \\
\hline 3. & Burung Tledekan & $\checkmark$ & $\checkmark$ & $\checkmark$ & • \\
\hline 4. & Burng Toucan & $\checkmark$ & $\checkmark$ & $\checkmark$ & - \\
\hline 5. & $\begin{array}{l}\text { Burung Kakatua } \\
\text { Jambul Kaning }\end{array}$ & $\checkmark$ & $\checkmark$ & $\checkmark$ & $*$ \\
\hline 6. & Burung Gagek & $\checkmark$ & $\checkmark$ & $\checkmark$ & • \\
\hline 7. & Burung Dara & $\checkmark$ & $\checkmark$ & $\checkmark$ & • \\
\hline 8. & Burung Nuri Hijau & $\checkmark$ & $\checkmark$ & $\checkmark$ & - \\
\hline 9. & Burugg Kurtul & $\checkmark$ & $\checkmark$ & $\checkmark$ & • \\
\hline 10. & Burung Jenjang & $\checkmark$ & $\checkmark$ & $\checkmark$ & • \\
\hline 11. & Burung Cilepuk & $\checkmark$ & $\checkmark$ & $*$ & $\bullet$ \\
\hline 12. & $\begin{array}{l}\text { Burung Kakatua } \\
\text { Ganggang }\end{array}$ & $\checkmark$ & $\checkmark$ & $\checkmark$ & $\bullet$ \\
\hline 13. & $\begin{array}{c}\text { Burung Belibis } \\
\text { Cokelat }\end{array}$ & $\checkmark$ & $\checkmark$ & $*$ & $\bullet$ \\
\hline 14 & Burmg Bulbul & $\checkmark$ & $\checkmark$ & $\checkmark$ & • \\
\hline 15. & Burung Walet & $\checkmark$ & $\checkmark$ & $\checkmark$ & $\bullet$ \\
\hline 16. & Burung Perkici & $\checkmark$ & $\checkmark$ & $\checkmark$ & $\bullet$ \\
\hline 17. & Burung Pelikan & $\checkmark$ & $\checkmark$ & $*$ & $*$ \\
\hline 18. & Burung Parkit & $\checkmark$ & $\checkmark$ & $\checkmark$ & * \\
\hline 19. & Burung Opior & $\checkmark$ & $\checkmark$ & $\checkmark$ & $\bullet$ \\
\hline 20. & Burung Nuri Pelangi & $\checkmark$ & $\checkmark$ & * & $\bullet$ \\
\hline
\end{tabular}




\begin{tabular}{|c|c|c|c|c|c|}
\hline 21. & Burung Nuri Abu & $\checkmark$ & $\checkmark$ & $\checkmark$ & . \\
\hline 22. & Burung Loon & $\checkmark$ & $\checkmark$ & * & - \\
\hline 23. & Burung Kolibri & $\checkmark$ & $\checkmark$ & $\checkmark$ & * \\
\hline 24 & Bunung Kallom & $\checkmark$ & $\checkmark$ & $\checkmark$ & - \\
\hline 25 . & Burung Elang Emas & $\checkmark$ & $\checkmark$ & $\checkmark$ & - \\
\hline 26 & Burung Elang Bandol & $\checkmark$ & $\checkmark$ & $\checkmark$ & - \\
\hline 27. & Burung Pegar & $\checkmark$ & $\checkmark$ & $\checkmark$ & - \\
\hline 28. & Burung Onta & $\checkmark$ & $\checkmark$ & $\checkmark$ & * \\
\hline 29. & Burung Betet Kelapa & $\checkmark$ & $\checkmark$ & * & - \\
\hline 30 & Burng Belikis Polos & $\checkmark$ & $\checkmark$ & $\checkmark$ & * \\
\hline \multicolumn{5}{|c|}{$\begin{array}{l}\text { Ket: } \\
\checkmark: \text { bisa } \\
+ \text { : bisa namun load lama }\end{array}$} & \\
\hline
\end{tabular}

\subsection{Pengujian Intensitas Cahaya}

Tabel 4.2 Pengujian Intensitas Cahaya

\begin{tabular}{|c|c|c|c|c|c|}
\hline \multirow{2}{*}{ No } & Nama Burung & \multicolumn{4}{|c|}{ Niai Intensitas Cahaya } \\
\hline & Burung Walik Jambu & $\checkmark$ & $\checkmark$ & $\checkmark$ & $\checkmark$ \\
\hline 1. & Burung Tengkek & $\checkmark$ & $\checkmark$ & $\checkmark$ & $*$ \\
\hline 2. & Burung Tledekan & $\checkmark$ & $\checkmark$ & $\checkmark$ & $*$ \\
\hline 4. & Burung Toucan & $\checkmark$ & $\checkmark$ & $\checkmark$ & $*$ \\
\hline 5. & Burung Kakatua Jambul Kuning & $\checkmark$ & $\checkmark$ & $\checkmark$ & $*$ \\
\hline 6. & Burung Gagak & $\checkmark$ & $\checkmark$ & $\checkmark$ & $*$ \\
\hline 7. & Burung Dara & $\checkmark$ & $\checkmark$ & $\checkmark$ & $*$ \\
\hline 8. & Burung Nuri Hijau & $\checkmark$ & $\checkmark$ & $\checkmark$ & $*$ \\
\hline 9. & Burung Kuntul & $\checkmark$ & $\checkmark$ & $\checkmark$ & $*$ \\
\hline 10. & Burung Jenjang & $\checkmark$ & $\checkmark$ & $\checkmark$ & $*$ \\
\hline 11. & Burung Cilepuk & $\checkmark$ & $\checkmark$ & $\checkmark$ & $*$ \\
\hline 12. & Burung Kakatua Ganggang & $\checkmark$ & $\checkmark$ & $\checkmark$ & $*$ \\
\hline 13. & Burung Belibis Cokelat & $\checkmark$ & $\checkmark$ & $\checkmark$ & $*$ \\
\hline 14. & Burung Bulbul & $\checkmark$ & $\checkmark$ & $\checkmark$ & $*$ \\
\hline 15. & Burung Walet & $\checkmark$ & $\checkmark$ & $\checkmark$ & $*$ \\
\hline 16. & Burung Perkici & $\checkmark$ & $\checkmark$ & $\checkmark$ & $*$ \\
\hline
\end{tabular}

\begin{tabular}{|c|c|c|c|c|c|}
\hline 17. & Burung Pelikan & $r$ & $\checkmark$ & $r$ & + \\
\hline 18. & Burung Parkit & $\gamma$ & $\checkmark$ & $\checkmark$ & $*$ \\
\hline 19. & Burung Opior & $\gamma$ & $\checkmark$ & $\checkmark$ & $*$ \\
\hline 20. & Burung Nuri Pelangi & $\checkmark$ & $\checkmark$ & $\checkmark$ & $*$ \\
\hline 21. & Burung Nuri Abu & $\checkmark$ & $\checkmark$ & $\checkmark$ & $*$ \\
\hline 22. & Burung Loon & $\checkmark$ & $\checkmark$ & $\checkmark$ & ${ }^{*}$ \\
\hline 23. & Burung Kolibri & $\checkmark$ & $\checkmark$ & $\checkmark$ & * \\
\hline 24. & Burung Kalkun & $\checkmark$ & $\checkmark$ & $\checkmark$ & + \\
\hline 25. & Burung Elang Emas & $\checkmark$ & $\checkmark$ & $\checkmark$ & + \\
\hline 26. & Burung Elang Bandol & $\checkmark$ & $\checkmark$ & $\checkmark$ & + \\
\hline 27. & Burung Pegar & $\checkmark$ & $\checkmark$ & $\checkmark$ & + \\
\hline 28. & Burung Onta & $r$ & $\checkmark$ & $\checkmark$ & * \\
\hline 29. & Burung Betet Kelapa & $\checkmark$ & $\checkmark$ & $\checkmark$ & + \\
\hline 30. & Burung Belibis Polos & $\checkmark$ & $\checkmark$ & $\checkmark$ & * \\
\hline
\end{tabular}

Kesimpulan dari hasil pengujian intensitas cahaya pada tabel diatas adalah pada nilai intensitas cahaya yaitu $(2,7 C d),(3,6 C d)$, dan $(6,4 C d)$ marker dapat terdeteksi dengan baik karena terdapat cahaya yang cukup untuk menerangi marker, Sedangkan nilai intensitas 65,6 $\mathrm{Cd}$ marker dapat terdeteksi namun load lama karena terhalang oleh sinar. Maka dapat disimpulkan bahwa cahaya sangat mempengaruhi detail dari marker yang discan agar dapat terdeteksi dengan baik.

\subsection{Pengujian User}

Pengujian pada user atau kuisioner dilakukan untuk mengetahui kepuasan pengguna dalam mengimplementasikan aplikasi pengenalan burung endemik Indonesia, respond tampilan aplikasi, respond augmented reality, dan respond kemudahan menggunakan aplikasi. 
Tabel 4.3 Pengujian User

\begin{tabular}{|c|c|c|c|c|}
\hline \multirow[b]{2}{*}{ No } & \multirow[b]{2}{*}{ Pertanyam } & \multicolumn{3}{|c|}{ Respord Pengguma } \\
\hline & & Baik & $\begin{array}{l}\text { Culapp } \\
\text { Baik }\end{array}$ & Kurang \\
\hline 1. & $\begin{array}{l}\text { Bugainana tamplan peda aplikasi } \\
\text { Pemanfadtan Augmented Reality Delam } \\
\text { Dumia Pendidikan Untuk Mengenal } \\
\text { Spesies Burung di Indonesia Berbesis } \\
\text { Anchoid? }\end{array}$ & 18 & 2 & - \\
\hline 2. & $\begin{array}{l}\text { Bagaimana informasi yang di sampaikan } \\
\text { pada aplikasi Pemanfaztan Angmented } \\
\text { Reality Dalam Dumia Pendidikan Untuk } \\
\text { Mengenal Spesies Burung di Indoneaia } \\
\text { Berbasis Anciroid? }\end{array}$ & 15 & 5 & - \\
\hline 3. & $\begin{array}{l}\text { Bagrimana objek yang di tampillan pada } \\
\text { aplikasi Pemanfastan Augmented Reality } \\
\text { Dalam Dunia Pendidikan Untuk } \\
\text { Mengenal Spesies Burung di Indonesia } \\
\text { Berbasis Android? }\end{array}$ & 15 & 4 & 1 \\
\hline 4. & $\begin{array}{l}\text { Bageinana kemudahan nenggmakan } \\
\text { Pemanfastan Augmented Reality Dalam } \\
\text { Duria Pendidikan Untuk. Mengenal } \\
\text { Spesies Bunung di Indonesia Berbesis } \\
\text { Ancroid? }\end{array}$ & 16 & 3 & 1 \\
\hline & Jumlah & 64 & 14 & 2 \\
\hline
\end{tabular}

Keterangan :

Dari 20 responden didapatkan hasil untuk poin 1 mengenai tampilan aplikasi sebanyak 90\% reponden mengatakan baik dan $10 \%$ responden cukup baik. Kemudian poin 2 mengenai informasi yang di sampaikan oleh aplikasi sebanyak $75 \%$ responden mengatakan baik dan $25 \%$ responden cukup baik. Untuk poin 3 mengenai objek 3D yang di tampilkan sebanyak $75 \%$ responden mengatakan baik, 20\% cukup baik, dan 5\% kurang. Dan poin 4 mengenai kemudahan penggunaan aplikasi sebanyak $80 \%$ responden mengatakan baik, $15 \%$ cukup baik, dan $5 \%$ kurang. Dengan total hasil $80 \%$ poin baik, $17,5 \%$ poin cukup baik dan 2,5\% poin kurang.

\section{KESIMPULAN DAN SARAN}

\subsection{Kesimpulan}

Setelah dilakukanya pengujian pada aplikasi Pemanfaatan Augmented Reality Dalam Dunia Pendidikan Untuk Mengenal Spesies Burung di Indonesia Berbasis Android maka penulis mendapatkan kesimpulan sebagai berikut :

1. Fitur aplikasi dapat dijalankan tidak ada masalah.

2. Hasil pengujian aplikasi pada beberapa sistem adalah aplikasi dapat terinstal dan berjalan pada smartphone dengan minimum RAM 4 GB dan sistem operasi minimal Lollipop. Saat pengujian dilakukan semua fitur dapat digunakan dengan baik.

3. Berdasarkan pengujian jarak terhadap marker dapat diketahui jarak ideal agar marker dapat ter-scan dengan baik adalah antara $10 \mathrm{~cm}, 30 \mathrm{~cm}$, sedangkan pada jarak $50 \mathrm{~cm}$ marker tidak dapat terdeteksi dengan baik karena terdapat kendala pada marker yang di scan tidak dapat terdeteksi secara jelas dan detail.

4. Kesimpulan dari hasil pengujian intensitas cahaya adalah pada nilai $(2,7),(3,6)$,dan $(6,4)$ marker dapat terdeteksi dengan baik karena terdapat cahaya yang cukup untuk menerangi marker, Sedangkan nilai intensitas 65,6 marker dapat terdeteksi namun load lama karena terhalang oleh sinar. Maka dapat disimpulkan bahwa cahaya sangat mempengaruhi detail dari marker yang discan agar dapat terdeteksi dengan baik.

5. Dari 20 responden didapatkan hasil untuk poin 1 mengenai tampilan aplikasi sebanyak $90 \%$ reponden mengatakan baik dan $10 \%$ responden cukup baik. Kemudian poin 2 mengenai informasi yang di sampaikan oleh aplikasi sebanyak $75 \%$ responden mengatakan baik dan 25\% responden cukup baik. Untuk poin 3 mengenai objek 3D yang di tampilkan sebanyak $75 \%$ responden mengatakan baik, 20\% cukup baik, dan 5\% kurang. Dan poin 4 mengenai kemudahan penggunaan aplikasi sebanyak $80 \%$ responden mengatakan baik, $15 \%$ cukup baik, dan 5\% kurang. Dengan total hasil $80 \%$ poin baik, $17,5 \%$ poin cukup baik dan 2,5\% poin kurang.

\subsection{Saran}

Berdasarkan penelitian yang telah dilakukan maka penulis dapat memberikan saran-saran untuk pengembangan selanjutnya karena penelitian ini masih terdapat banyak kekurangan, sehingga untuk penyempurnaan dapat ditambahkan :

1. Penambahan video gift pada objek 3D agar objek Burung lebih menarik.

2. Penambahan animasi lebih diperbanyak agar terlihat lebih menarik.

3. Pengembangan dalam bentuk VR untuk menambah minat belajar dan pengetahuan mengenai Burung Indonesia khususnya Burung Endemik Indonesia.

\section{DAFTAR PUSTAKA}

[1] Abdurrahman, I., Darusalam, U., \& Benrahman. (2020). Perancangan Pembelajaran Bangun Ruang 3 Dimensi Berbasis Android. Jurnal Media Informatika Budidarma.

[2] Andriansyah, M. (2012). Retrieved Mei 23, 2020, from Pembuatan Game 3 Dimensi Lost In Jungle dengan Menggunakan Unity 3D Game Engine: http://repository.amikom.ac.id/files/Publikasi_1 0.21 .0535

[3] Arka. (2019). Aplikasi Media Pembelajaran Tulang Manusia Menggunakan Augmented Reality (AR) Berbasis Android.

[4] Asry, A. I. (2019). Penerapan Augmented Reality dengan Metode Marker Based Tracking pada Maket Rumah Virtual. Jurnal Informatika. 
[5] Avis. (2011). Analisis Metode Occlusion Based Pada Augmented Reality Studi Kasus : Interaksi Dengan Objek Virtual Secara Real Time Menggunakan Gerakan Marker. Surabaya.

[6] Candra. (2014). Perancangan Sistem Interaksi Berbasis Teknologi Augmented Reality pada Sampul Media Promosi Cetak.

[7] Defandra, G. (2010, Mei). Retrieved Maret 19, 2020, from Sejarah Augmented Reality: http://belajar-ar.blogspot.com/2010/05/sejarahaugmented-reality_28.html

[8] Endah, A. (2010, September 13). Alam Endah's Blog. Retrieved from Binatang (Fauna) Endemik Indonesia: https://alamendah.org/2010/09/13/binatangfauna-endemik-indonesia/

[9] Enterprise, J. (2016). Blender Untuk Pemula. Jakarta: PT Elex Media Komputindo.

[10] Hamzati, N. S., \& Aunurohim. (2013). Keanekaragaman Burung di Beberapa Tipe Habitat di Bentang Alam Mbeliling Bagian Barat, Flores. Jurnal Sains dan Seni Pomits.

[11] Kirana, R. C. (2013). Retrieved Maret 19, 2020, from Bab 2 Penggolongan Makhluk Hidup: http://ratih2701.wordpress.com/bab-1-ciri-ciridan-kebutuhan-makhluk-hidup/bab-2penggolongan-makhluk-hidup/

[12] Kurniawan. (2011). Retrieved Mei 23, 2020, from Apa itu Android. Pengertian Android Secara Singkat.: http://thekaku.com/apa-ituAndroid-pengertian-Android-secara-singkat

[13] Laxuardy, S. (2012). Retrieved Mei 23, 2020, from Augmented Reality : Masa Depan Interaktivitas:

https://tekno.kompas.com/read/2012/04/09/1235 4384/Augmented.Reality.Masa.Depan.Interaktiv itas
[14] Mangunjaya, F. M. (2017). Pelestarian Satwa Langka untuk Keseimbangan Ekosistem: Penuntun Sosialisasi Fatwa MUI No 4, 2014, tentang Fatwa Pelestarian Satwa Langka untuk Menjaga Keseimbangan Eksosistem. MUI pusat.

[15] Mustaqim, I., \& Kurniawan, N. (2017). PENGEMBANGAN MEDIA PEMBELAJARAN BERBASIS AUGMENTED REALITY. Jurnal Edukasi Elektro.

[16] Ohan, \& Budiawati. (2015). Pemanfaatan aneka ragam burung dalam kontes burung kicau dan dampaknya terhadap konservasi burung di alam: Studi kasus di Kota Bandung, Jawa Barat. Pros Sem Nas Masy Biodiv, 747-752.

[17] Pressman, R. (2002). Rekayasa Perangkat Lunak Pendekatan Praktisi. Yogyakarta.

[18] Sabilillah, M. A. (2018). APLIKASI PENGENALAN RAMBU LALU LINTAS MENGGUNAKAN AUGMENTED REALITY BERBASIS ANDROID. Institut Nasional Malang.

[19] Sudarmilah, E., \& dkk. (2015). Augmented Reality Edugame Senjata Tradisional Indonesia. Surakarta.

[20] Sulistyadi, E. (2010). Kemampuan Kawasan Nir-Konservasi dalam Melindungi KelestarianBurung Endemik Dataran Rendah Pulau Jawa (Studi Kasus di Kabupaten Kebumen). Jurnal Biologi Indonesia, 237-253.

[21] Supriatna, J. (2008). Melestarikan Alam Indonesia. Jakarta: Yayasan Obor Indonesia.

[22] Turut, R. (2011). 42 Burung Ocehan Populer. Depok: Penebar Swadaya.

[23] Wiguna, R. D. (2019). Pengenalan Alat Musik Tradisional Indonesia Menggunakan Augmented Reality. Institut Teknologi Malang. 